Document downloaded from:

http://hdl.handle.net/10251/157577

This paper must be cited as:

Infante, D.; Qian, G.; Miguélez, MH.; Giner Maravilla, E. (2019). Analysis of the effect of outof-phase biaxial fatigue loads on crack paths in cruciform specimens using XFEM. International Journal of Fatigue. 123:87-95. https://doi.org/10.1016/j.ijfatigue.2019.01.019

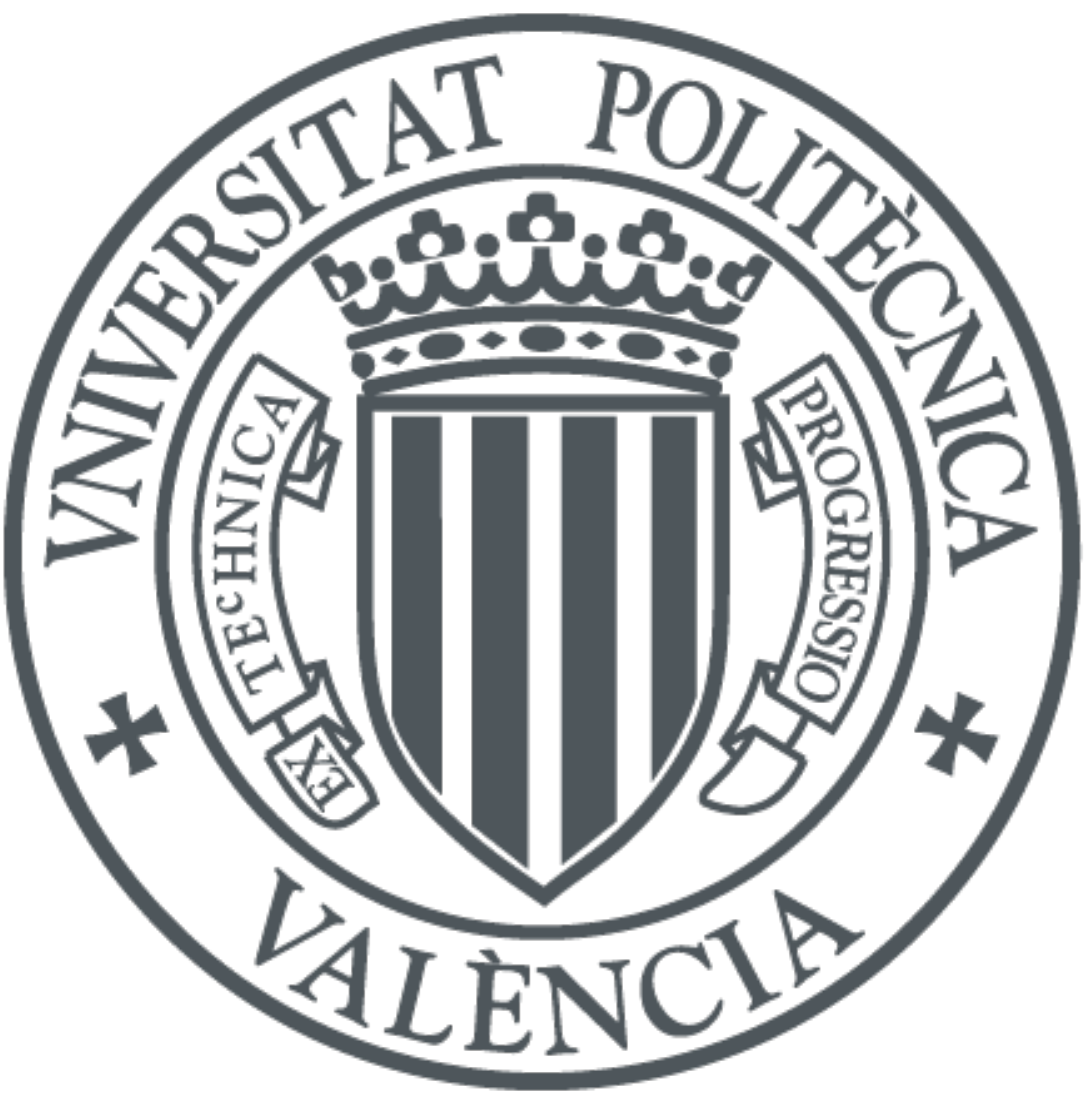

The final publication is available at

https://doi.org/10.1016/j.ijfatigue.2019.01.019

Copyright Elsevier

Additional Information 


\title{
Analysis of the effect of out-of-phase biaxial fatigue loads on crack paths in cruciform specimens using XFEM
}

\author{
Diego Infante ${ }^{1}$, Guian Qian ${ }^{2}$,Henar Miguélez ${ }^{1}$, Eugenio Giner ${ }^{3, *}$ \\ (1) Department of Mechanical Engineering. Universidad Carlos III de Madrid, Avda. de la Universidad \\ 30, 28911 Leganés, Madrid, Spain \\ (2) State Key Laboratory for Nonlinear Mechanics (LNM), Institute of Mechanics, Chinese Academy of \\ Sciences, Beijing 100080, China \\ (3) Centre of Research in Mechanical Engineering - CIIM, Department of Mechanical and Materials \\ Engineering, Universitat Politècnica de València. Camino de Vera, 46022 Valencia, Spain
}

\section{* Corresponding author: eginerm@mcm.upv.es}

\section{$\underline{\text { Abstract }}$}

In the present research work, a numerical crack growth analysis using linear elastic fracture mechanics is carried out paying attention to the crack paths that grow in the central part of cruciform specimens under biaxial fatigue loads. The crack propagation in this type of specimens has been studied using the extended finite element method (XFEM). The objective is to analyse the effect of different phase angles under biaxial fatigue loads and to assess the different orientation criteria for nonproportional loading, benefiting from the advantages of XFEM. The crack path and the stress intensity factor range of a crack either aligned or inclined to the load directions have been investigated using different crack orientation criteria. Symmetrical branching is predicted for an initial crack inclined at $45^{\circ}$ with phase angle of loading equal to $90^{\circ}$ and $180^{\circ}$. The numerical results are in good agreement with the experimental observations found in the literature, although the study reveals important differences in the crack path predictions depending on the orientation criteria.

\section{$\underline{\text { Keywords }}$}

XFEM; cruciform specimen; biaxial fatigue loading; crack paths 


\section{Introduction}

Multiaxial stresses can be found in many engineering structures, for example in the automotive or aeronautical industry. Furthermore, fatigue has been identified as responsible of a large amount of structural failures [1]. The biaxial stress state is one of the most studied cases since it is found on the surface of many mechanical components, where crack initiation usually takes place [2]. Thus, the scope of this study has been limited to a biaxial stress state under pure mode I, pure mode II and mixed mode (I+II)

of fracture mechanics. During last decades, the development of new fatigue testing machines has allowed to investigate different biaxial loading paths (in-phase, out-ofphase, different frequencies, variable amplitude, etc.) in different engineering materials [3-7]. Tubular [8], solid cylindrical [9] or cruciform specimens [7] are the most common specimens that have been analyzed in the literature [10].

Under proportional fatigue loading, a crack may propagate either co-planar or at a certain deviation angle, mode I or mode II controlled (either perpendicular to the maximum normal stress or governed by the maximum shear stress) depending on the material and type of loading [11]. Due to the proportionality of loads, directions of maximum normal and shear stresses are kept constant with time, and therefore the crack growth direction can be easily ascertained.

Under non-proportional mixed mode I+II, a crack can either grow co-planar (mode I or mode II controlled), or propagate at a certain deviation angle or branch in different cracks $[4,12]$. Co-planar crack growth has been reported for cracked cruciform specimens under equibiaxial and in-phase loading in several works found in the literature [3,13-17]. In addition, symmetric crack branching (crack bifurcation) from an initial crack $45^{\circ}$ inclined to the loading axis has been reported in cracked cruciform specimens 
under out-of-phase loading conditions [3-5,18]. Furthermore, it has been shown that nonsingular terms have no significant influence on crack deflection in cruciform specimens. However, non-singular terms, as the T-stress, are good predictors of crack stability [6].

The objective of the present work is to analyse numerically the effect of different phase angle of loading and initial crack inclinations on the predicted crack path under biaxial fatigue loading, benefiting from the advantages offered by XFEM simulations. With this aim, different criteria for nonproportional loading found in the literature are compared. Finally, the effect of the displacement ratio and phase angle of loading on the crack orientation is assessed for the first crack growth step.

\section{Materials and methods}

\subsection{Cruciform specimen and initial crack geometry}

A symmetrical cruciform specimen is employed for the biaxial study, as is shown in Fig. 1.The specimen geometry is in accordance to the international program NESC $[19,20]$. A centred initial crack either aligned or inclined to the load directions is located at the centre of the specimen. The inclination angle values examined are $\beta=0^{\circ}, 15^{\circ}, 30^{\circ}$ and $45^{\circ}$, and the initial crack length $(2 a)$ is $36 \mathrm{~mm}$.
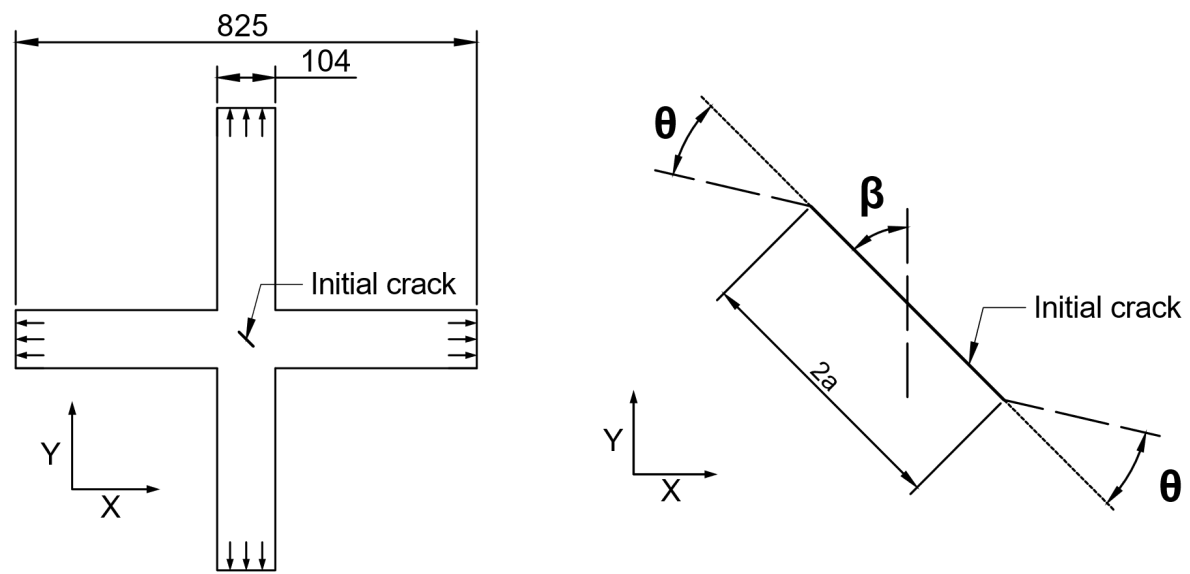

Figure 1: Sketch of the cruciform specimen problem with a centred crack and definition of initial inclination angle $(\beta)$ and local angle of propagation $(\theta)$. 


\subsection{Loading}

Loads are controlled by prescribed displacements $U_{\mathrm{x}}$ and $U_{\mathrm{y}}$ applied to each of the specimen arms. In all loading cases studied, the maximum displacement applied to both arms is kept constant and equal to $0.076 \mathrm{~mm}$. In addition, the same displacement ratio between the minimum and maximum displacements $\left(U_{\min }\right.$ and $\left.U_{\max }\right)$ prescribed in a cycle (Eq. 1) and frequency are set for both arms. Displacement loads are defined according to Eqs. (2) and (3), being $\delta_{\mathrm{xy}}$ the phase shift angle, $T$ the time period, $U_{\mathrm{m}}$ the mean displacement and $U_{\mathrm{a}}$ the amplitude displacement:

$$
\begin{aligned}
& R_{d x}=R_{d y}=\frac{U_{\min }}{U_{\max }} \\
& U_{x}=U_{m}+U_{a} \cos \left(\frac{2 \pi t}{T}\right) \\
& U_{y}=U_{m}+U_{a} \cos \left(\frac{2 \pi t}{T}+\delta_{x y}\right)
\end{aligned}
$$

Numerical crack paths are obtained with a phase angle of $0^{\circ}, 90^{\circ}$ and $180^{\circ}$ and a positive displacement ratio $R_{\mathrm{d}}$ of 0.1 in order to minimize crack closure effects. The loading cases considered are shown in Fig. 2. When $\delta_{\mathrm{xy}}$ is $0^{\circ}$, loads are in-phase, and the loading path is a straight line with slope equal to 1 . Thus, the biaxiality ratio keeps constant during the cycle and the case is clearly proportional.

When $\delta_{\mathrm{xy}}$ is $90^{\circ}$, loads are out-of-phase, and the loading path is a circle with centre at $(\mathrm{Um}, \mathrm{Um})$. When $\delta_{\mathrm{xy}}$ is $180^{\circ}$, loads are again out-of-phase and the crack path is a straight line with a slope of -1 . 

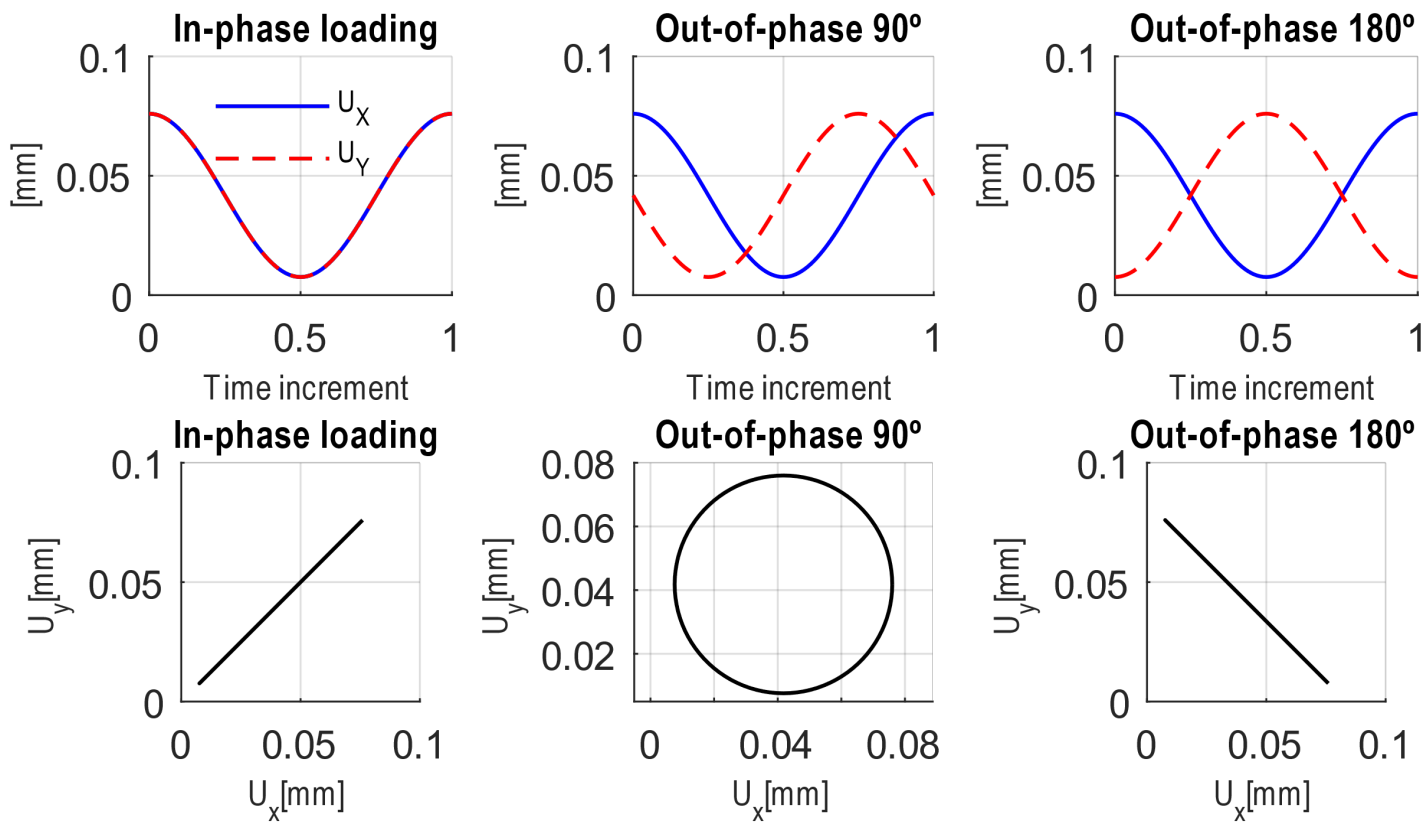

Figure 2: In-phase and out-of-phase $90^{\circ}$ and $180^{\circ}$ loading paths applied with $R_{\mathrm{d}}=0.1$ and $U_{\max }=0.076 \mathrm{~mm}$.

\subsection{Numerical model}

An Abaqus implementation of the extended finite element method (XFEM) [21] is employed to model crack propagation. Thus, the mathematical discontinuity introduced by means of XFEM enables the crack growth simulation without the necessity of remeshing. Inertial effects are not taken into account, and a quasi-static analysis is performed. A small scale yielding condition is assumed at crack tip. The material behaviour is taken as elastic, with $E=206 \mathrm{GPa}$ and $v=0.3$, under a plane strain condition. The mesh element size is $0.5 \mathrm{~mm}$ at the specimen centre.

The crack is successively propagated as follows. First, stress intensity factors (SIFs) are calculated using the domain independent interaction integral for each crack tip (further details can be found in [21]). Then, a fatigue crack propagation criterion is applied, and the crack is extended $1.25 \mathrm{~mm}$ in the predicted direction. The mesh and crack extension sizes have been analyzed previously in order to optimize the computational cost and accuracy of the results. 


\subsection{Fatigue crack propagation}

In two-dimensional linear-elastic fracture mechanics and under mixed loading conditions that vary with time, the stress state governed by $K_{\mathrm{I}}$ and $K_{\mathrm{II}}$ corresponding to the singular term at crack tip in polar coordinates $(r, \theta)$ is given by [22]:

$$
\begin{aligned}
& \sigma_{\theta \theta}(t, \theta)=\frac{K_{\mathrm{I}}(t)}{\sqrt{2 \pi r}}\left[\frac{3}{4} \cos \left(\frac{\theta}{2}\right)+\frac{1}{4} \cos \left(\frac{3 \theta}{2}\right)\right]+\frac{K_{\mathrm{II}}(t)}{\sqrt{2 \pi r}}\left[\frac{-3}{4} \sin \left(\frac{\theta}{2}\right)-\frac{3}{4} \sin \left(\frac{3 \theta}{2}\right)\right] \\
& \tau_{r \theta}(t, \theta)=\frac{K_{\mathrm{I}}(t)}{\sqrt{2 \pi r}}\left[\frac{1}{4} \sin \left(\frac{\theta}{2}\right)+\frac{1}{4} \sin \left(\frac{3 \theta}{2}\right)\right]+\frac{K_{\mathrm{II}}(t)}{\sqrt{2 \pi r}}\left[\frac{1}{4} \cos \left(\frac{\theta}{2}\right)+\frac{3}{4} \cos \left(\frac{3 \theta}{2}\right)\right]
\end{aligned}
$$

The trigonometric functions in Eq. (4) can be found in any basic book of fracture mechanics, e.g. [23]. After multiplying Eq. (4) by $\sqrt{ }(2 \pi r)$, the stress field expressions are modified in such a way that the influence of $r$ is cancelled:

$$
\begin{aligned}
& k_{\mathrm{I}}^{*}(t, \theta)=\sigma_{\theta \theta}(t, \theta) \sqrt{2 \pi r}=K_{\mathrm{I}}(t)\left[\frac{3}{4} \cos \left(\frac{\theta}{2}\right)+\frac{1}{4} \cos \left(\frac{3 \theta}{2}\right)\right]+K_{\mathrm{II}}(t)\left[\frac{-3}{4} \sin \left(\frac{\theta}{2}\right)-\frac{3}{4} \sin \left(\frac{3 \theta}{2}\right)\right] \\
& k_{\mathrm{II}}^{*}(t, \theta)=\tau_{r \theta}(t, \theta) \sqrt{2 \pi r}=K_{\mathrm{I}}(t)\left[\frac{1}{4} \sin \left(\frac{\theta}{2}\right)+\frac{1}{4} \sin \left(\frac{3 \theta}{2}\right)\right]+K_{\mathrm{II}}(t)\left[\frac{1}{4} \cos \left(\frac{\theta}{2}\right)+\frac{3}{4} \cos \left(\frac{3 \theta}{2}\right)\right]
\end{aligned}
$$

Since Eqs. (5) are dimensionally equivalent to stress intensity factors, in Eqs. (5) we define the virtual stress intensity factors $k_{\mathrm{I}}{ }^{*}, k_{\mathrm{II}} *$ to assess the prospective angle $\theta$ for crack kinking (see Fig. 3). This assessment is performed via several criteria (reviewed below) that are based on $k_{\mathrm{I}} *$ or $k_{\mathrm{II}} *$ computed for different values of $t$ and $\theta$.

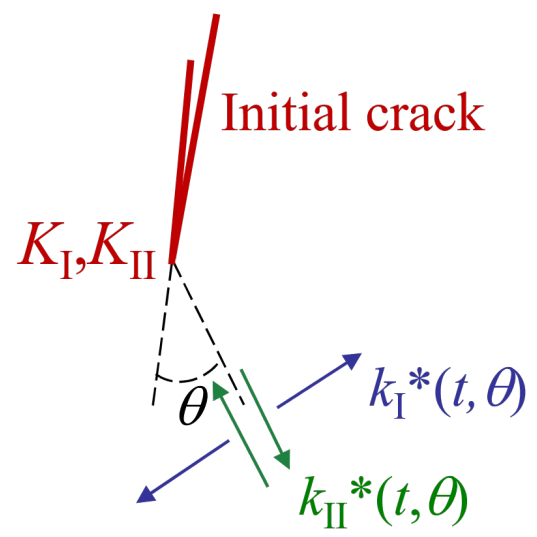

Figure 3: Sketch of the stress intensity factors associated with a virtual crack emanating from the initial crack.

Conceptually, some authors link $k_{\mathrm{I}}^{*}, k_{\mathrm{II}}^{*}$ to a virtual infinitesimally-branched 
crack emanating from the original crack with an angle $\theta$ [24]. It must be noted that negative values of $k_{\mathrm{I}}{ }^{*}$ have no physical meaning since a negative $k_{\mathrm{I}}{ }^{*}$ means that the normal stress field is compressive and the hypothetical crack faces overlap. Therefore, it should not be considered in the crack propagation. In this way, negative $k^{*}$ are set to zero.

In general, under proportional loading, a crack kinks in a direction where the tensile normal stress field (mode I stress intensity factor $k_{1}^{*}$ ) is maximum. Furthermore, this direction coincides with the direction of $k_{\mathrm{II}} *$ equal to zero, in accordance with the criterion of local symmetry [25], and with the direction of maximum $\Delta k_{1}^{*}$. Several criteria can be found in the literature following these observations such as the maximum tangential stress criterion [26], the maximum strain energy density criterion [27] and the maximum energy release rate [28].

Many authors have demonstrated that predicted angles given by the aforementioned criteria are very similar. It should be mentioned that these criteria can be modified in order to account for the effect of non-singular terms [29]. On the other hand, it has been verified that a crack can also propagate co-planar or mode II controlled at high mixed-mode loadings under certain circumstances [30]. However, this is not the general case. Therefore, we will assume that propagation is mode I controlled to simplify the study. Other types of propagation are out of the scope of this work.

Under nonproportional loading, the ratio of the stress intensity factor $K_{\mathrm{I}} / K_{\mathrm{II}}$ is not kept constant during the cycle as in proportional loading. Thus, it can be generally said that the direction of maximum $k_{\mathrm{I}}^{*}$ at different instants of a loading cycle $\left(k_{\mathrm{I}, \mathrm{max}} *\right)$ is not kept constant during the cycle. Under these conditions, Hourlier [31] examined three potential directions of crack orientation: the direction corresponding to the absolute $k_{\mathrm{I}, \max } *$ $\left(\max \left(k_{1}^{*}\right)\right)$, the direction where $\Delta k_{1} *$ is maximum $\left(\max \left(\Delta k_{1}^{*}\right)\right)$ and the direction where the 
crack growth rate is maximum. In addition, Dubourg and Lamacq [32] proposed the direction where the effective range of the circumferential stress is maximum along the cycle. The criterion was applied to fretting fatigue problems showing a good agreement. On the other hand, an extension of the criterion of local symmetry for nonproportional loading, $\min \left(\Delta k_{I I}{ }^{*}\right)$, was proposed by Giner et al. [33], where the crack orientation is the direction for which the shear stress range at the crack tip is minimized, $\min (\Delta \tau)$ [34]. Lastly, Highsmith [35] observed that direction of crack orientation usually falls between the $\max \left(k_{1}^{*}\right)$ and $\max \left(\Delta k_{1}^{*}\right)$ criteria. In this way, Highsmith employed a crack driving force, Eq. (6), combining the influence of both parameters following the work by Hourlier et al. [31] and Walker [36]. In this way, the mean stress influence is introduced into the crack orientation criterion for materials that show this dependence. In Eq. (6), the parameter $w$ weighs $k_{\mathrm{I}, \max }{ }^{*}$ and $\Delta k_{\mathrm{I}}{ }^{*}$, thus defining which one dominates the direction of orientation. The crack orientation angle is the one for which the crack driving force is maximized:

$$
\overline{\Delta k_{I}^{W *}(\theta)}=k_{I, \max }{ }^{1-w}(\theta) \Delta k_{I, \max }^{*}{ }^{w}(\theta)
$$

\section{Results}

The results are divided into five sections. The first three sections present the numerical crack path results for a phase angle of $0^{\circ}, 90^{\circ}$ and $180^{\circ}$. In each section, the numerical crack path is obtained for four different central crack inclinations $\left(0^{\circ}, 15^{\circ}, 30^{\circ}\right.$ and $\left.45^{\circ}\right)$ while keeping constant the rest of parameters. Finally, the fourth and fifth sections address the influence of the displacement ratio and the first crack kink, respectively, for an initial centred crack inclined at $45^{\circ}$.

\subsection{In-phase}

When the loads are in phase, $K_{\text {II }}$ remains zero during the loading cycle for any crack 
inclination, and the crack grows coplanar to the initial crack as is shown in Fig. 4. Thus, crack behaviour is a pure mode I. As is shown in Fig. 5, the prospective directions $\theta$ predicted by the $\min \left(\Delta k_{\mathrm{II}^{*}}\right), \max \left(k_{\mathrm{I}}^{*}\right)$ and $\max \left(\Delta k_{\mathrm{I}}^{*}\right)$ criterion do not vary with time during the loading cycle due to the proportionality of loads. This direction is $\theta=0^{\circ}$ (defined as in Fig. 1), which is in line with experimental observations found in the literature for the case of $\beta=0^{\circ}$ and $45^{\circ}[3,14,17]$.

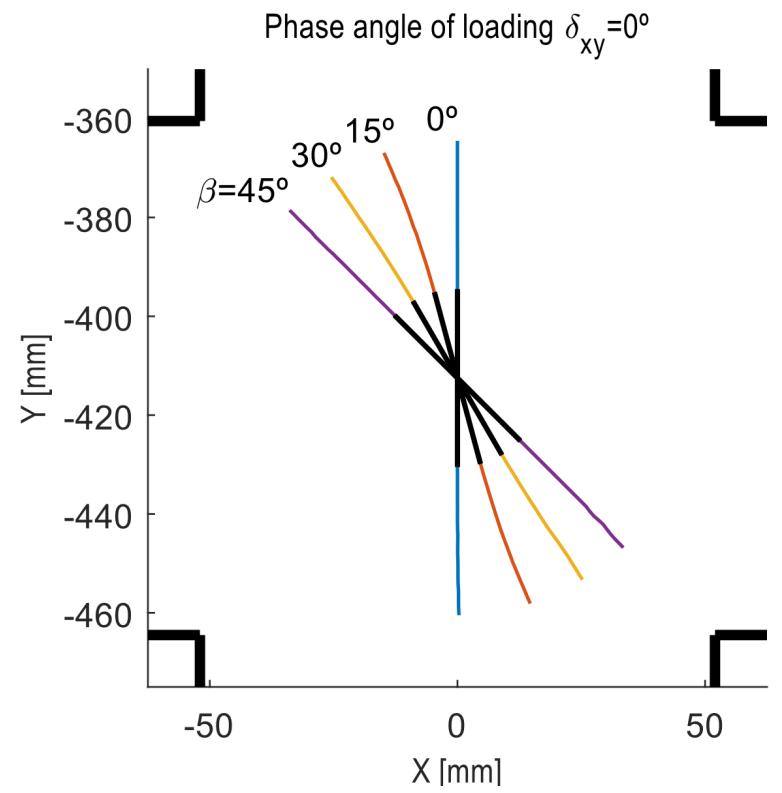

Figure 4: Numerical crack paths after 25 propagations for the four initial inclinations $\beta=0^{\circ}, 15^{\circ}, 30^{\circ}$ and $45^{\circ}$ with phase angle of loading $0^{\circ}$ (initial crack in black) using the $\max \left(\Delta k_{1}^{*}\right)$ criterion.
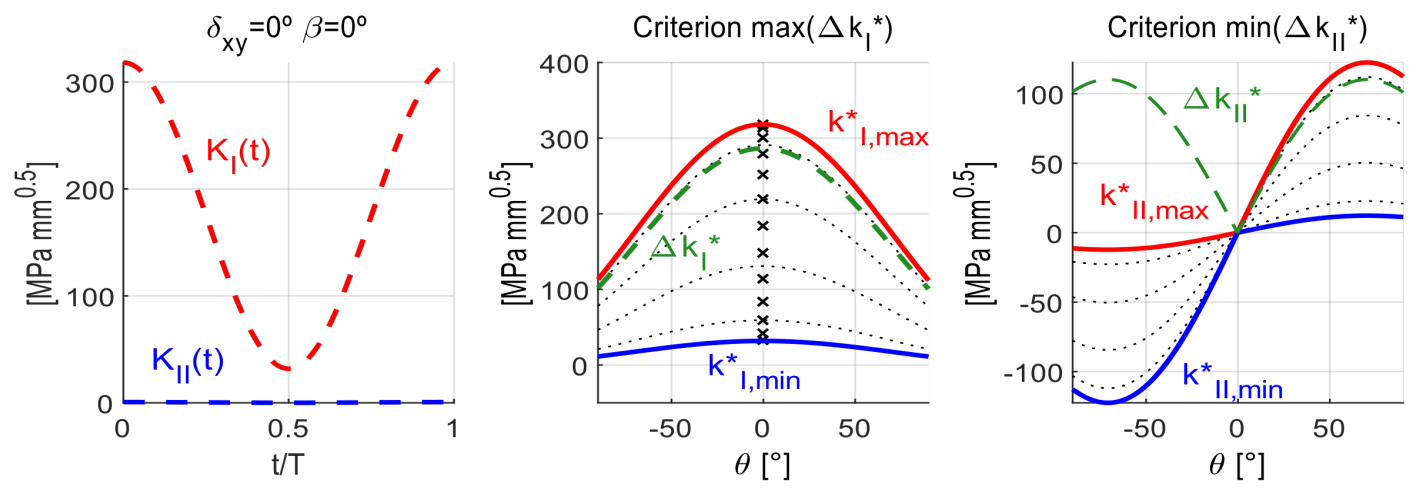

Figure 5: SIFs, $k_{\mathrm{I}} *(t, \theta)$ and $k_{\mathrm{II}} *(t, \theta)$ during a loading cycle for the initial centred crack for the case $\beta=0^{\circ}$ and $\delta_{\mathrm{xy}}=0^{\circ}$.

\subsection{Out-of-phase $180^{\circ}$}

When the phase angle of loading is $180^{\circ}$, three crack behaviours are found depending on the initial crack inclination $\beta$. When the crack is aligned with the loading directions 
$\left(\beta=0^{\circ}\right), K_{\text {II }}$ remains zero during the loading cycle. Therefore, the crack behaviour is a pure mode I and there is not crack kink. Furthermore, predicted crack paths agree with the experimental evidence found by Lee and Taylor [17].

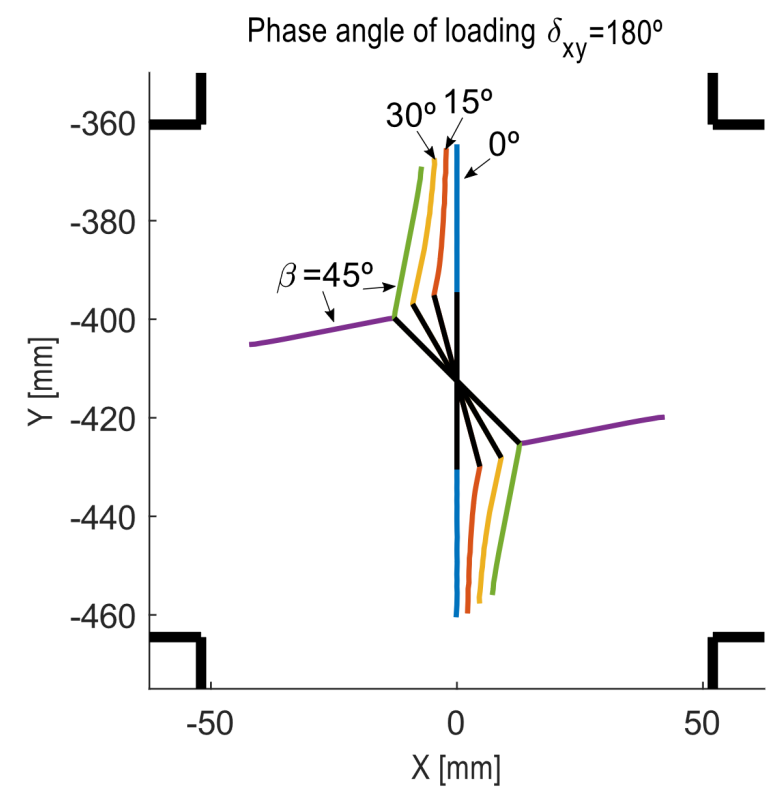

Figure 6: Numerical crack paths after 25 propagations for the four inclinations $\beta$ with phase angle of loading $180^{\circ}$ (initial crack in black) using the $\max \left(\Delta k_{1}^{*}\right)$ criterion.
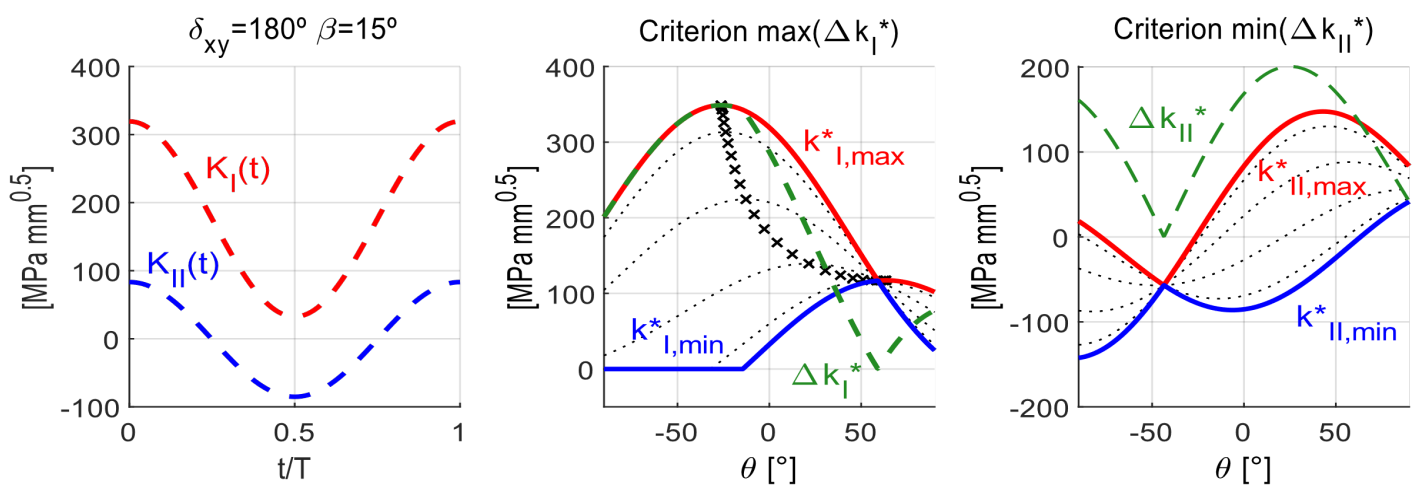

Figure 7: SIFs, $k_{1}^{*}(t, \theta)$ and $k_{1} *(t, \theta)$ during a loading cycle for the initial centred crack for the case $\beta=15^{\circ}$ and $\delta_{\mathrm{xy}}=180^{\circ}$.

When $\beta$ is either $15^{\circ}$ or $30^{\circ}$, the loading case is clearly non-proportional and mixed-mode (see Fig. 7 and 8). As is seen in Fig.7 and 8, the direction where $k_{\mathrm{I}}$ achieves its maximum (cross markers in subfigure for $\max \left(\Delta k_{1}^{*}\right)$ criterion) changes during the loading cycle. The predicted orientation by $\max \left(k_{\mathrm{I}}^{*}\right)$ coincides with the direction of 
$\max \left(\Delta k_{I^{*}}\right)$ for $\beta$ equal to $15^{\circ}$ and $30^{\circ}$. However, it is observed in Fig. 7 that $\min \left(\Delta k_{I I}{ }^{*}\right)$ is zero and the predicted direction does not coincide with the direction predicted by the $\max \left(\Delta k_{1}^{*}\right)$ criterion for both cases (see Fig. 7 and 8).
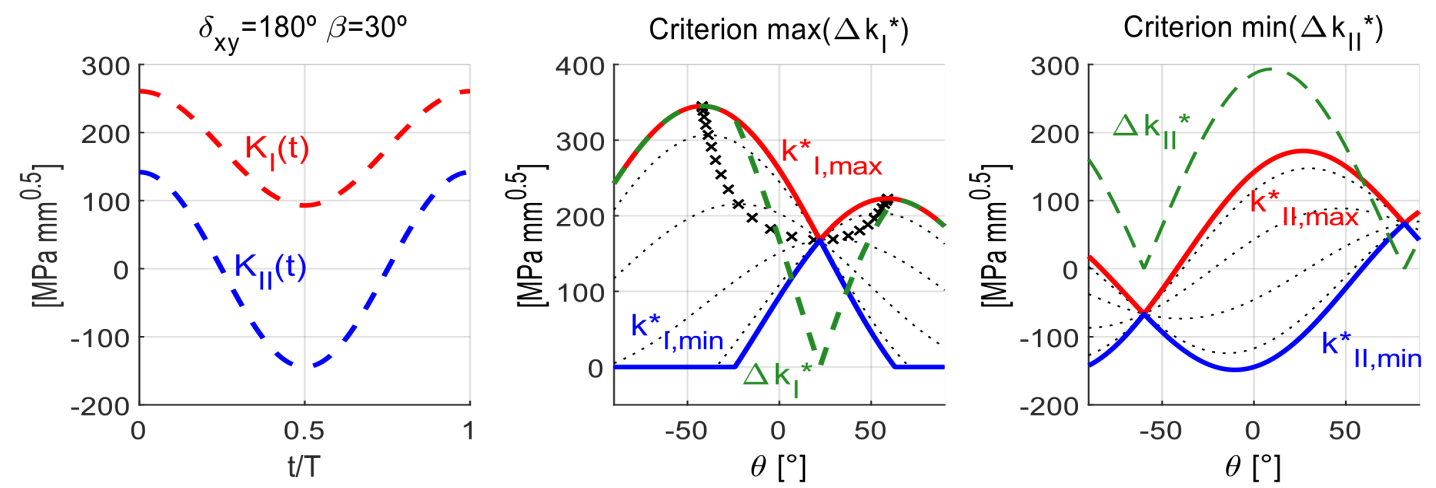

Figure 8: SIFs, $k_{1}^{*}(t, \theta)$ and $k_{1} *(t, \theta)$ along a cycle for the initial centred crack for the case $\beta=30^{\circ}$ and $\delta_{\mathrm{xy}}=180^{\circ}$.

When $\beta$ is $45^{\circ}$, the loading case is again mixed-mode and non-proportional. However, in this case $K_{\text {I }}$ does not vary during the loading cycle while $K_{\text {II }}$ changes. As is shown in Fig. 9, there are two directions $\left(\theta= \pm 50^{\circ}\right)$ where $k_{\mathrm{I}}^{*}$ and $\Delta k_{\mathrm{I}}^{*}$ achieve their absolute maximum. Furthermore, $\min \left(\Delta k_{\mathrm{II}}{ }^{*}\right)$ is zero and its predicted direction $\left(\theta= \pm 70.5^{\circ}\right)$ does not coincide with the $\max \left(\Delta k_{\mathrm{I}}{ }^{*}\right)$ predicted direction. Therefore, the crack is expected to branch symmetrically into two cracks with respect to the initial crack.

This result was first observed by Qian et al. [4] and recently by Neerukatti et al. [5]. Qian et al. [4] observed experimentally that the crack initially bifurcates symmetrically into two cracks at $50^{\circ}-60^{\circ}$. Within $1 \mathrm{~mm}$, the crack bifurcates to $70^{\circ}$ and finally propagates along the direction of axes. We point out that Lee and Taylor [17] only observed kinking of the crack into one of the branches. However, this fact may be consequence of misalignment of the specimen or local effects such as the microstructure at that region. 

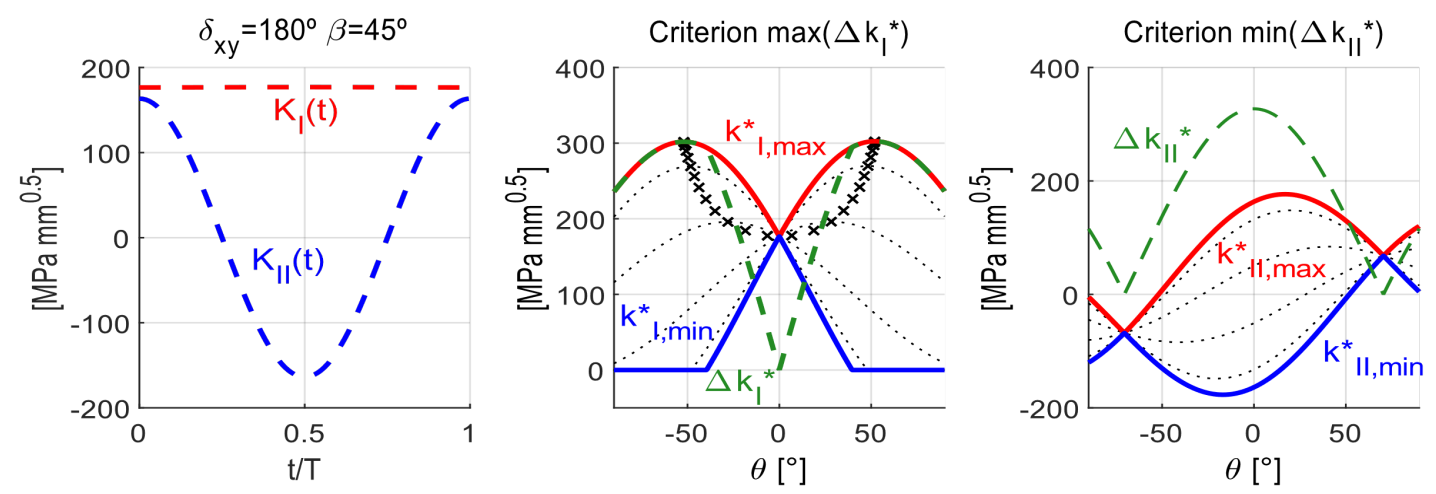

Figure 9: $\operatorname{SIFs}, k_{\mathrm{I}}^{*}(t, \theta)$ and $k_{\mathrm{I}} *(t, \theta)$ along a cycle for the initial centred crack for the case $\beta=45^{\circ}$ and $\delta_{\mathrm{xy}}=180^{\circ}$.

\subsection{Out-of-phase $90^{\circ}$}

When the phase angle of loading is $90^{\circ}$, the crack path predicted is very close to the predicted crack path with phase angle of loading equal to $180^{\circ}$. Nevertheless, the predicted kink angles are smaller in this case. Mall and Perell [3] found experimentally less kinking in symmetrical bifurcated cracks under $90^{\circ}$ phase angle of loading than in $180^{\circ}$ phase angle of loading. As can be seen in Fig. 10, the crack path is straight for the initial crack aligned with the load axis, and symmetric branching is predicted for an initial crack with an inclination of $45^{\circ}$.

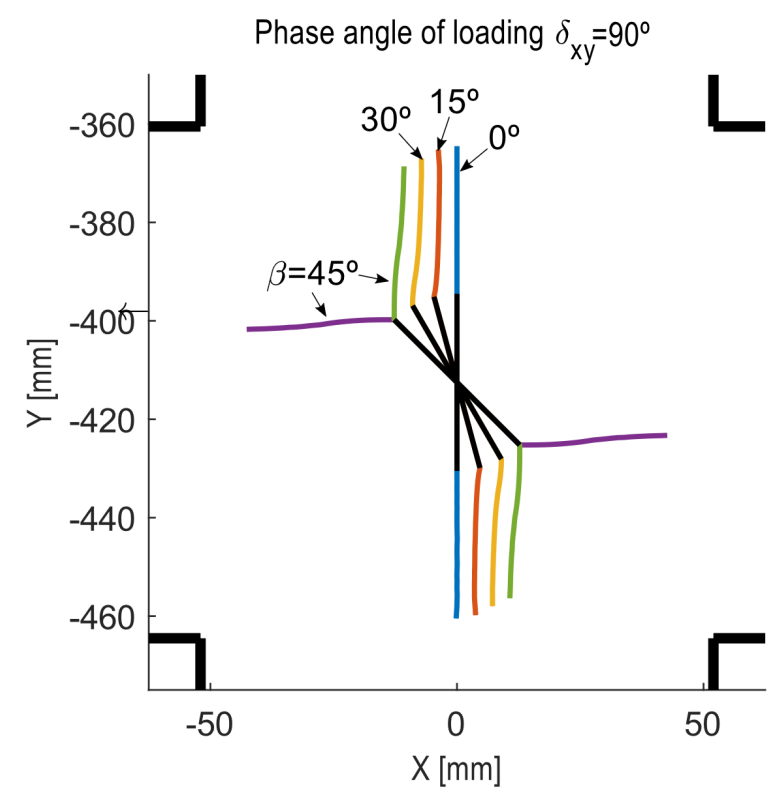

Figure 10: Numerical crack paths after 25 propagations for the four inclinations $\beta$ with phase angle of loading $90^{\circ}$ (initial crack in black) using the $\max \left(\Delta k^{*}\right)$ criterion. 

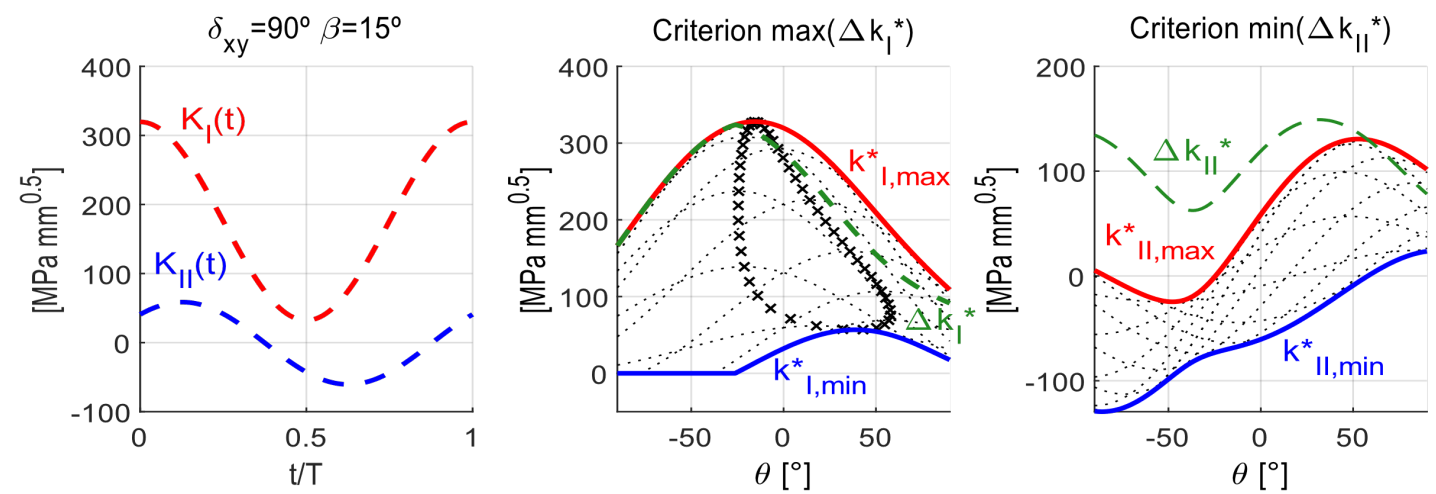

Figure 11: $\operatorname{SIFs}, k_{1}^{*}(t, \theta)$ and $k_{1}^{*}(t, \theta)$ during a loading cycle for the initial centred crack for the case $\beta=15^{\circ}$ and

$$
\delta_{\mathrm{xy}}=90^{\circ} .
$$

The differences found between $180^{\circ}$ and $90^{\circ}$ phase angles of loading are in the $k_{\mathrm{I}}{ }^{*}$ and $k_{\mathrm{II}} *$ curves along a cycle. As is shown in Fig. 11 , relative $k_{\mathrm{I}, \max } *$ values during a cycle (cross markers in subfigures for $\max \left(\Delta k_{1}^{*}\right)$ criterion) follow a loop shape. Furthermore, in comparison with the same inclination case of phase angle of loading equal to $180^{\circ}$, the angle predicted by $\min \left(\Delta k_{I I} *\right)\left(\theta=-36.5^{\circ}\right)$ is less sharp (for $\delta_{\mathrm{xy}}=180^{\circ}$ it was $\left.\theta=-43.5^{\circ}\right)$, and it does not coincide with the angle predicted by $\max \left(\Delta k_{1}^{*}\right)\left(\theta=-26.25^{\circ}\right)$.

These facts are more pronounced when the initial inclination is $45^{\circ}$ as is shown in Fig. 12. As in the case of $180^{\circ}$ phase angle of loading, symmetric branching is predicted on both crack tips when $\beta=45^{\circ}$. Mall and Perell [3] observed experimentally the same fact for an initial crack inclined $45^{\circ}$ with phase angle of loading equal to $90^{\circ}$. However, Neerukatti et al. [5] observed the initial crack kinking only in one branch although the major crack tried to split unsuccessfully to secondary cracks. 

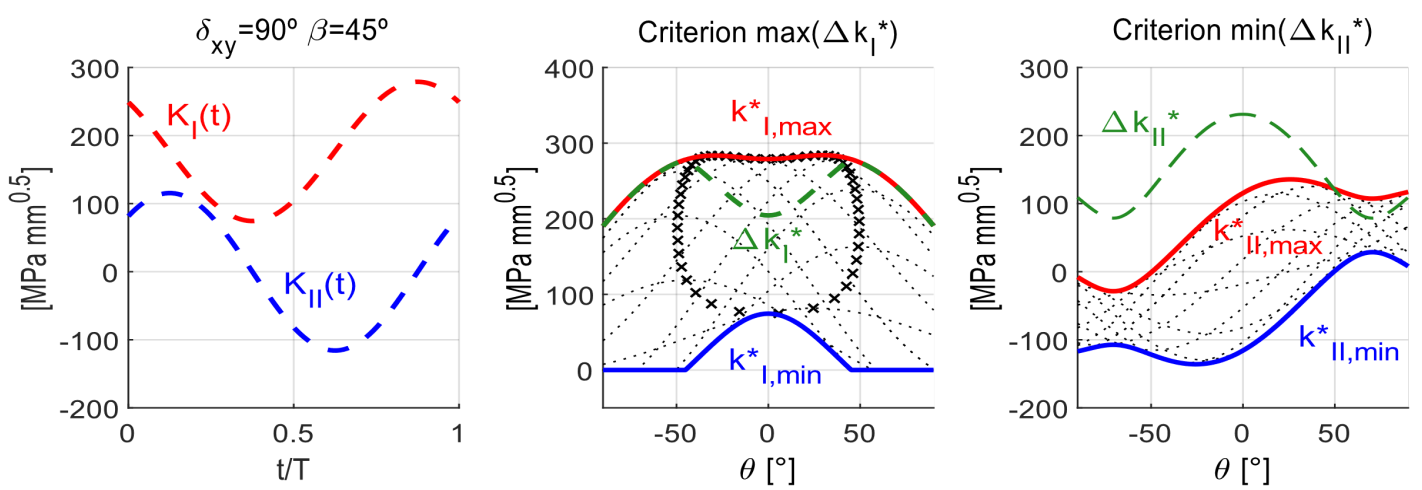

Figure 12: SIFs, $k_{1}^{*}(t, \theta)$ and $k_{\Perp} *(t, \theta)$ during a loading cycle for the initial centred crack for the case $\beta=45^{\circ}$ and $\delta_{\mathrm{xy}}=90^{\circ}$.

Fig. 13 displays the predicted crack paths at one of the crack tips (the behaviour at the other crack tip is symmetric) for the different orientation criteria: $\max \left(k_{1}{ }^{*}\right)$, $\min \left(\Delta k_{\mathrm{II}}{ }^{*}\right), \max \left(\Delta k_{\mathrm{I}}^{*}\right)$ and $\max \left(\Delta k_{\mathrm{I}}^{\mathrm{w} *}\right)(w=0.3$ and 0.7$)$ for the case $\beta=45^{\circ}$ and $\delta_{\mathrm{xy}}=90^{\circ}$. It is evident that significant differences can be found between the predicted crack paths. It is shown that the crack predicted by the criterion $\max \left(k_{\mathrm{I}}^{*}\right)$ is a straight line. The crack paths predicted by $\min \left(\Delta k_{I_{I}}{ }^{*}\right)$ and $\max \left(\Delta k_{I^{*}}\right)$ are different from the beginning, but the crack path predicted by $\max \left(\Delta k_{\Gamma^{*}}\right)$ gets close to the crack path predicted by $\min \left(\Delta k_{\mathrm{II}}{ }^{*}\right)$ as the crack grows. In addition, it is observed that the approach proposed by Highsmith [35] can be employed to fit the predicted crack in cases for which the experimental crack lies between the results obtained by $\max \left(\Delta k_{\mathrm{I}}^{*}\right)$ and $\max \left(k_{\mathrm{I}}^{*}\right)$ criterion. 


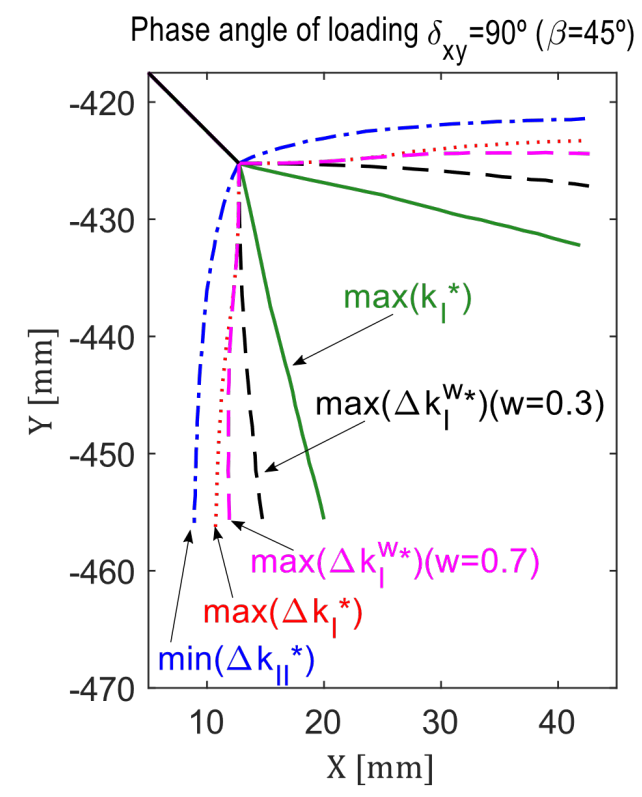

Figure 13: Numerical crack paths after 25 propagations for $\beta=45^{\circ}$ and $\delta_{\mathrm{xy}}=90^{\circ}$ predicted by the orientation criteria $\max \left(k_{\mathrm{I}}^{*}\right), \min \left(\Delta k_{\mathrm{II}}{ }^{*}\right), \max \left(\Delta k_{\mathrm{I}}{ }^{\mathrm{w}}\right)(w=0.3$ and 0.7$)$ and $\max \left(\Delta k_{\mathrm{I}}{ }^{*}\right)$. Initial inclined crack: solid black line.

Figure 14 shows the predicted crack paths at one of the crack tips (predicted crack paths for the other crack tip are symmetric) with $\max \left(k_{\Gamma^{*}}\right), \min \left(\Delta k_{I^{*}}\right)$ and $\max \left(\Delta k_{\Gamma^{*}}\right)$ for $\beta=45^{\circ}$ and $\delta_{\mathrm{xy}}=180^{\circ}$. Again, significant differences can be observed between the predicted crack paths. The differences are similar to those found for the $\delta_{\mathrm{xy}}=90^{\circ}$ case. The crack path predicted by $\max \left(k_{\mathrm{I}}^{*}\right)$ is again a straight line. In addition, the predicted bifurcation angle is greater for the $\min \left(\Delta k_{I I}{ }^{*}\right)$ criterion than for the angle predicted by $\max \left(\Delta k_{I^{*}}\right)$. Experimental crack paths observed in [3-5] with phase angle of loading equal to $180^{\circ}$ are similar to the predictions obtained with $\min \left(\Delta k_{\Pi}{ }^{*}\right)$ and $\max \left(\Delta k_{\Gamma^{*}}\right)$. The shape of the experimental crack is closer to the predictions obtained by the $\min \left(\Delta k_{\mathrm{II}}{ }^{*}\right)$ criterion. Further investigations by varying specimen dimensions and loads are necessary to confirm this point. 


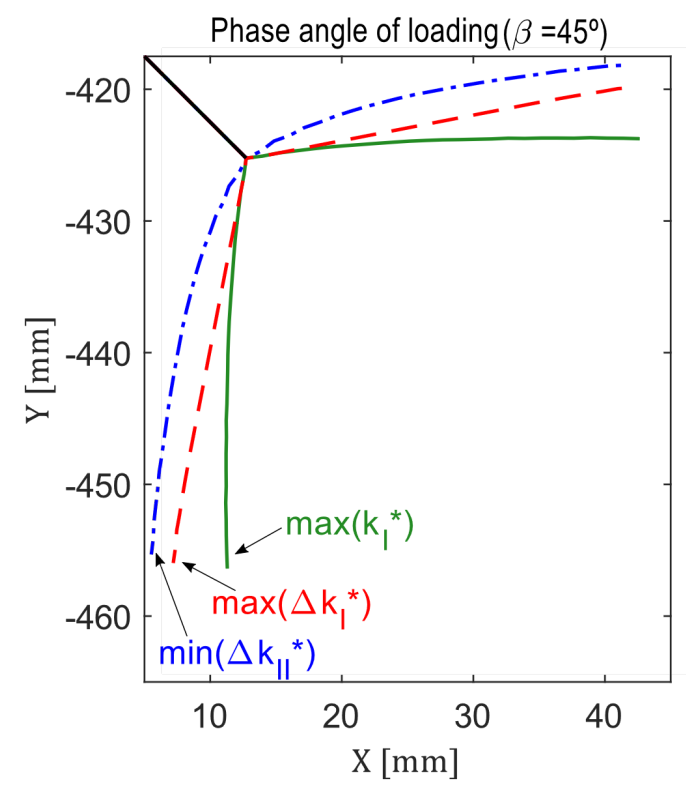

Figure 14: Numerical crack path after 25 propagations for $\beta=45^{\circ}$ and $\delta_{\mathrm{xy}}=180^{\circ}$ predicted by the orientation criteria $\max \left(k_{\mathrm{I}}^{*}\right), \min \left(\Delta k_{\mathrm{II}}{ }^{*}\right)$ and $\max \left(\Delta k_{\mathrm{I}}^{*}\right)$. Initial inclined crack: solid black line.

Mall and Perel [3] observed crack bifurcation from an initial crack inclined $45^{\circ}$ under phase angle of loading equal to $180^{\circ}$ and $90^{\circ}$ and co-planar growth under equibiaxial in-phase loading. Fig. 15 shows a picture of the experimental crack paths described above, published in [3]. In qualitative terms, it is observed a good correlation with the predicted crack paths shown in Fig. 13 and 14 with the criterion of $\min \left(\Delta k_{\mathrm{II}} *\right)$ and $\max \left(\Delta k_{1}^{*}\right)$. However, it must be noted that the geometry and material may relevantly influence the crack path. It cannot be concluded which criterion has a better agreement with the experimental evidence. 


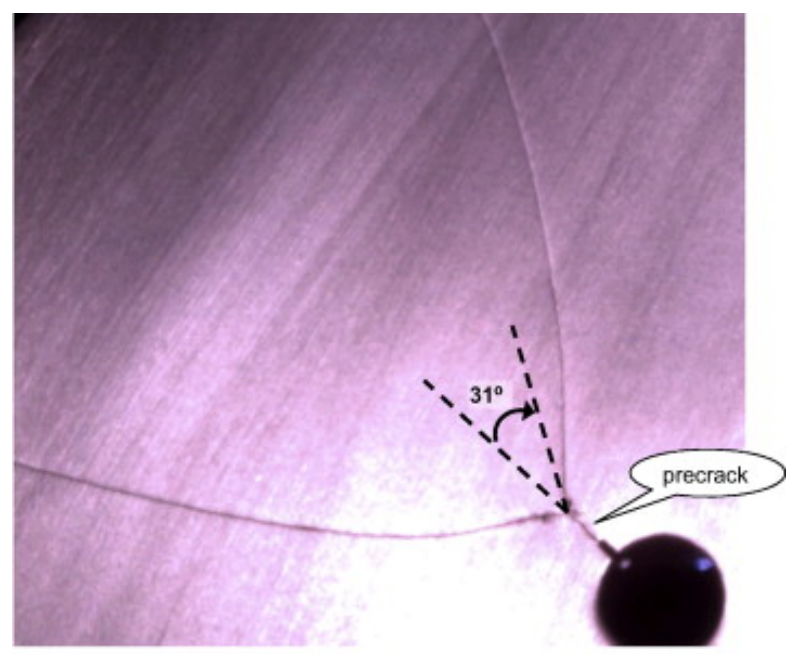

(a)

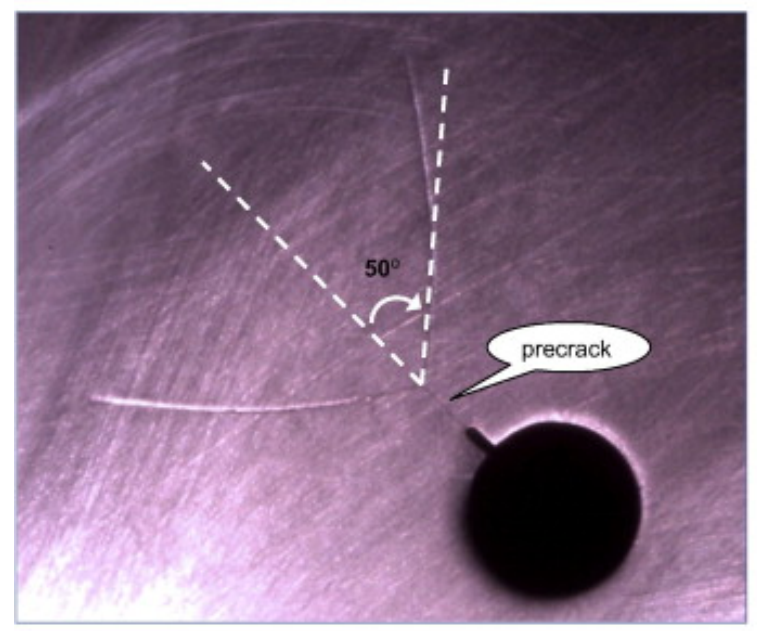

(b)

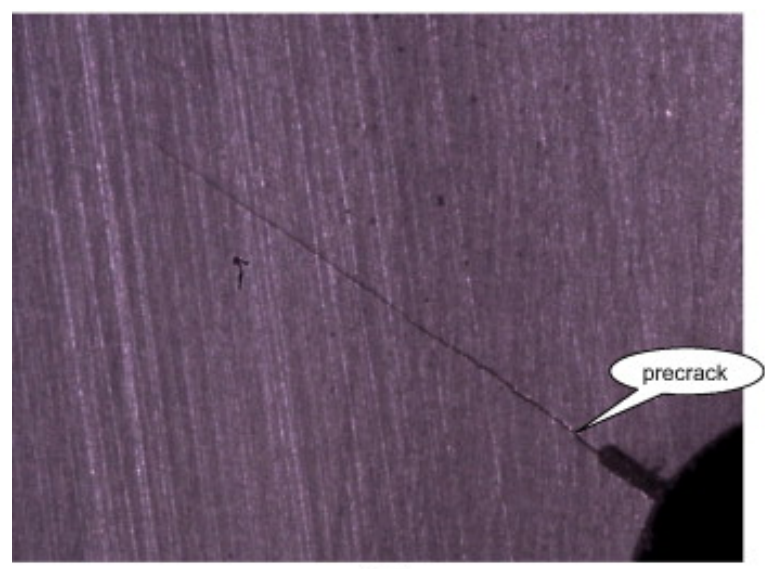

(c)

Figure 15: Experimental evidence found by Mall and Perel [3] (reproduced with permission of Elsevier) for cracks originating from a precrack inclined $45^{\circ}$ with the loading axes with phase difference (a) $90^{\circ}$, (b) $180^{\circ}$ and (c) $0^{\circ}$.

On the other hand, Qian et al. [4] showed that the shear stress range in mode II stress intensity factor is almost zero after the bifurcation of the crack in 4 branches when 
the phase angle of loading is $180^{\circ}$. Fig. 16 shows the mode I and mode II stress intensity factor ranges $\left(\Delta \mathrm{K}_{\mathrm{I}}\right.$ and $\left.\Delta \mathrm{K}_{\mathrm{II}}\right)$ along the crack path predicted by the orientation criteria $\max \left(k_{I^{*}}\right), \min \left(\Delta k_{\mathrm{II}}{ }^{*}\right)$ and $\max \left(\Delta k_{\mathrm{I}}^{*}\right)$ for the case $\beta=45^{\circ}$ and $\delta_{\mathrm{xy}}=180^{\circ}$. As can be seen, $\Delta \mathrm{K}_{\mathrm{II}}$ achieves a value close to zero after few propagations for the path predicted by the $\min \left(\Delta k_{\mathrm{II}}{ }^{*}\right)$ criterion. This condition takes longer to be achieved by the $\max \left(\Delta k_{\mathrm{I}} *\right)$ criterion, whereas it is not achieved by the $\max \left(k_{\mathrm{I}}{ }^{*}\right)$ criterion. This again suggests that the $\min \left(\Delta k_{\mathrm{II}}{ }^{*}\right)$ captures in a better way the mechanical behaviour governing crack orientation, as was commented by Giner et al. in [33], for the analogous $\min (\Delta \tau)$ criterion.
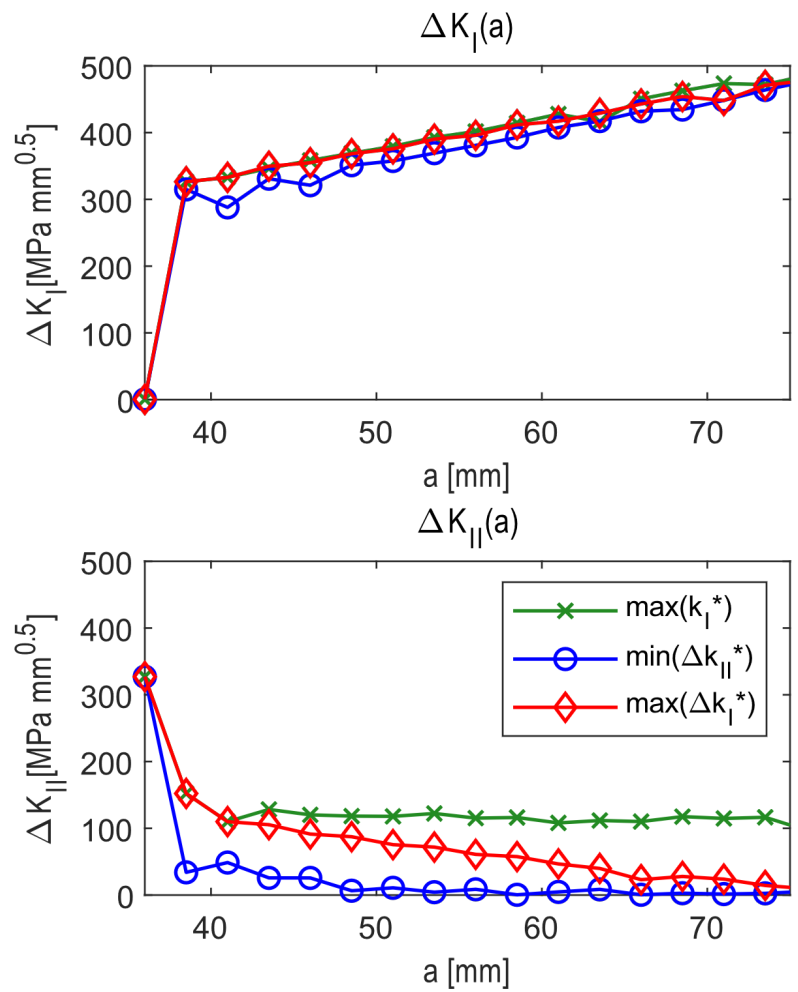

Figure 16: Mode I stress intensity factor range (top) and mode II stress intensity factor range (bottom) vs. crack length for $\beta=45^{\circ}$ and $\delta_{\mathrm{xy}}=180^{\circ}$ predicted by the orientation criteria $\max \left(k_{\mathrm{I}}^{*}\right), \min \left(\Delta k_{\mathrm{II}}{ }^{*}\right)$ and $\max \left(\Delta k_{\mathrm{I}} *\right)$.

\subsection{Displacement ratio}

In the previous sections, the displacement ratio applied in both axes is kept constant in all the cases $\left(R_{\mathrm{d}}=0.1\right)$. In this section, the influence of the displacement ratio of the 
displacement-controlled loads applied at both arms on the first crack orientation is assessed numerically. The case analyzed corresponds to an inclination $\beta=45^{\circ}$ and two outof-phase loadings: $90^{\circ}$ and $180^{\circ}$. The same displacement ratio is applied on both arms. Four different orientation criteria are applied: $\min \left(\Delta k_{I^{*}}\right), \max \left(\Delta k_{I^{*}}\right), \max \left(k_{I^{*}}\right)$ and $\max \left(\Delta k_{\mathrm{I}}{ }^{\mathrm{W} *}\right)$. The studied displacement ratio interval ranges from -1 to 0.8 .

Figure 17 shows the predicted crack orientation angle against the displacement ratio $R_{\mathrm{d}}$, showing large differences depending on the orientation criteria. In general, all the applied criteria predict symmetric branching with respect to the initial crack direction, except the $\max \left(k_{I^{*}}\right)$ criterion for the case $\delta_{\mathrm{xy}}=90^{\circ}$ and displacement ratio higher than 0.4 . We point out that Fig. 17 only shows the predicted angle in one of the bifurcated branches. It is important to remark that the criterion $\min \left(\Delta k_{\mathrm{II}^{*}}\right)$ leads to an angle prediction that is independent of $R_{\mathrm{d}}$. On the contrary, and for the out-of-phase $90^{\circ}$, the criterion $\max \left(k_{\mathrm{I}}{ }^{*}\right)$ predicts no kinking when the displacement ratio is above 0.4 . However, when the displacement ratio is below $0.4, \max \left(\Delta k_{\mathrm{I}}^{*}\right)$ tends to predict the same direction as the $\max \left(k_{\mathrm{I}}^{*}\right)$ criterion. In addition, it can be observed that, as the parameter $w$ increases, the angle predicted by the $\max \left(\Delta k_{\mathrm{I}}{ }^{\mathrm{w} *}\right)$ criterion is closer to the direction predicted by the $\max \left(\Delta k_{1}^{*}\right)$ criterion.
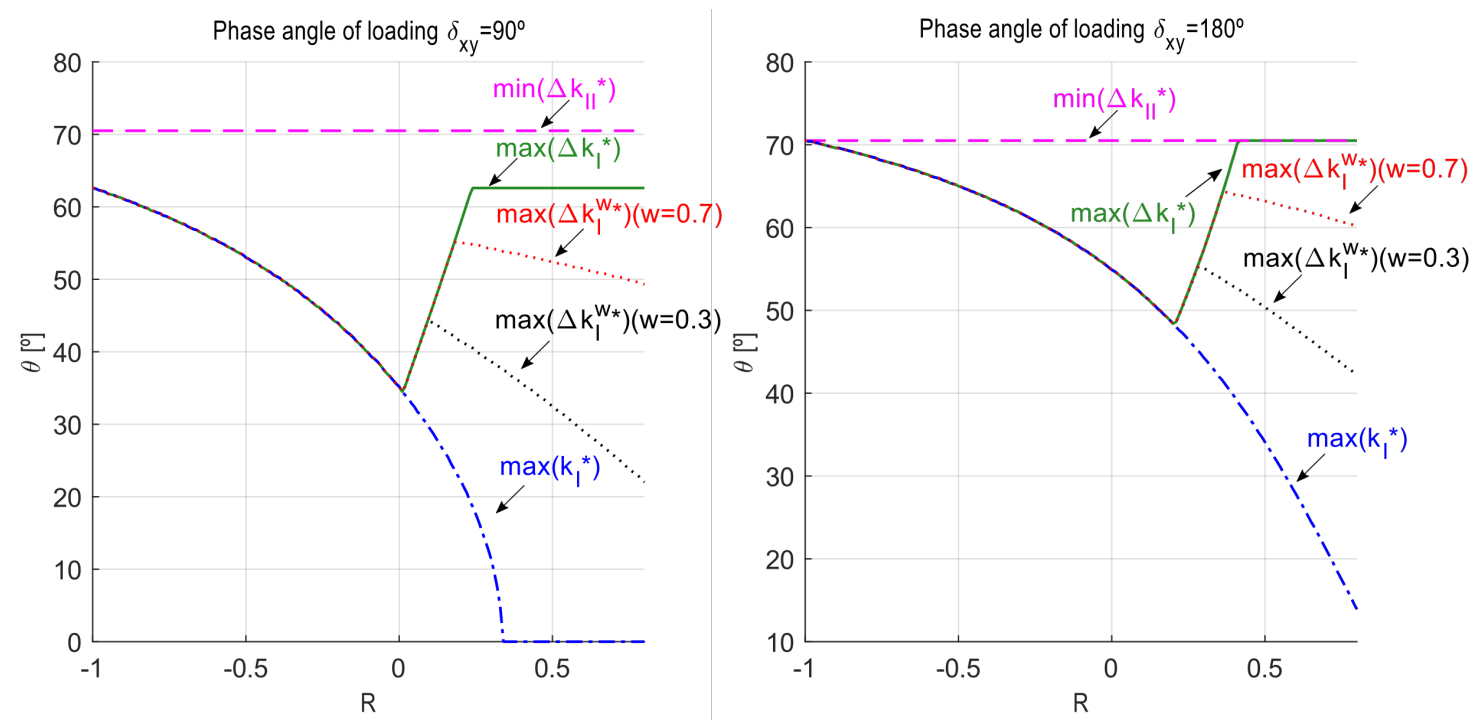

Figure 17: Bifurcation angle predicted at the crack tip of the initial inclined crack $\left(\beta=45^{\circ}\right)$ versus displacement ratio 
applied on both arms when the phase angle of loading is $90^{\circ}$ and $180^{\circ}$.

\subsection{Phase angle of loading}

In this section, we analyze the effect of phase of loading for the case $\beta=45^{\circ}$ and $R_{\mathrm{d}}=0.1$

on both arms. Similar to the previous section, different criteria are applied to predict the crack propagation of a straight initial crack of length $36 \mathrm{~mm}$. Fig. 18 shows the predicted crack orientation angle against the phase angle for the outlined case. The parameter $w$ is set to 0.3 for the calculation of the $\max \left(\Delta k_{\mathrm{I}}{ }^{\mathrm{w} *}\right)$ criterion. As can be seen, all criteria predict that the crack will propagate without kinking for small phase loading angles. In addition, all criteria predict bifurcation above a certain value of phase angle of loading. It is interesting to observe that crack bifurcation is predicted abruptly after a phase angle of loading of about $40^{\circ}$ for the criterion of $\min \left(\Delta k_{I} *\right)$, predicting a bifurcation angle of $70.5^{\circ}$ that is independent of the phase loading angle.

The bifurcation angles predicted by the rest of criteria increase with the phase angle in a smooth way. Note that the phase angle value that triggers bifurcation is greater than $50^{\circ}$ for the rest of criteria. Further experimental tests should be carried out to compare these predictions. 


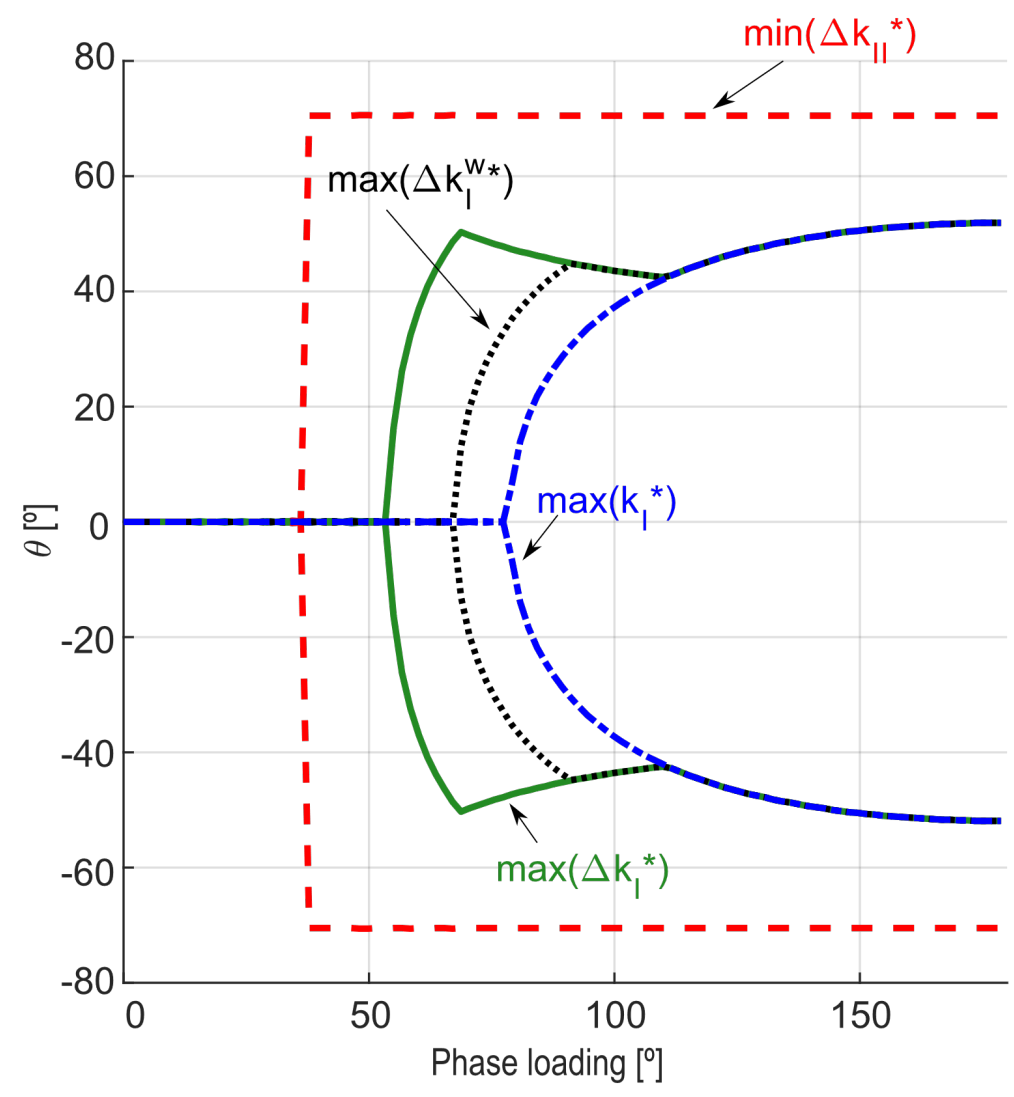

Figure 18: Bifurcation angle predicted at the crack tip of the initial inclined crack $\left(\beta=45^{\circ}\right)$ versus phase angle of loading applied on both arms with a displacement ratio equal to 0.1 .

\section{Conclusions}

Crack propagation has been numerically analysed for a cruciform specimen under out-ofphase biaxial fatigue loads. The influence of the phase angle of loading and displacement ratio has been assessed using XFEM and applying different criteria found in the literature for non-proportional loading. A parametric study has been carried out thanks to the advantages of XFEM. It enables the study of the effect of out-of-phase fatigue biaxial loads and initial crack inclination on crack paths.

In the case of either initial cracks aligned with a load direction or in-phase loading, cracks do not change the initial orientation. In the cases of $90^{\circ}$ and $180^{\circ}$ phase loading, an initial crack inclined $45^{\circ}$ to the load direction can bifurcate into two cracks growing 
symmetrically with respect to the initial crack plane. The numerical results agree with the experimental observations found in the literature. It can be concluded that crack paths predicted using different orientation criteria, such as $\max \left(\Delta k_{\mathrm{I}}^{*}\right), \max \left(k_{\mathrm{I}^{*}}\right)$ and $\min \left(\Delta k_{\mathrm{II}^{*}}\right)$, can be significant different from each other. Further experimental testing should be carried out in order to confirm the numerical predictions discussed in this research.

\section{Acknowledgments}

The authors gratefully acknowledge the financial support given by the Spanish Ministry of Economy and Competitiveness and the FEDER program through the project DPI201789197-C2-1-R, DPI2017-89197-C2-2-R and DPI2014-56137-C2-2-R and the FPI subprogram associated to the project with the reference BES-2015-072070. The support of the Generalitat Valenciana, Programme PROMETEO 2016/007, is also acknowledged.

\section{References}

[1] Fuchs HO, Stephens RI, Saunders H. Metal Fatigue in Engineering (1980). J Eng Mater Technol 1981;103:346. doi:10.1115/1.3225026.

[2] Schijve J. Biaxial Fatigue of Metals, 2016, p. 1-23. doi:10.1007/978-3-31923606-3_1.

[3] Mall S, Perel VY. Crack growth behavior under biaxial fatigue with phase difference. Int J Fatigue 2015;74:166-72. doi:10.1016/j.ijfatigue.2015.01.005.

[4] Qian C, Wang M-. Symmetric branching of mode II and mixed-mode fatigue crack growth in a stainless steel 1996;118:356-61. doi:10.1115/1.2806818.

[5] Neerukatti RK, Datta S, Chattopadhyay A, Iyyer N, Phan N. Fatigue crack propagation under in-phase and out-of-phase biaxial loading. Fatigue Fract Eng Mater Struct 2018;41:387-99. doi:10.1111/ffe.12690.

[6] Breitbarth E, Besel M. Fatigue crack deflection in cruciform specimens subjected to biaxial loading conditions. Int J Fatigue 2018;113:345-50. 
doi:10.1016/j.ijfatigue.2018.04.021.

[7] Makinde A, Thibodeau L, Neale KW. Development of an apparatus for biaxial testing using cruciform specimens. Exp Mech 1992;32:138-44.

doi:10.1007/BF02324725.

[8] Abreu LMP, Costa JD, Ferreira JAM. Fatigue behaviour of AlMgSi tubular specimens subjected to bending-torsion loading. Int J Fatigue 2009;31:1327-36. doi:10.1016/j.ijfatigue.2009.03.004.

[9] Carpinteri A, Brighenti R. Part-through cracks in round bars under cyclic combined axial and bending loading. Int J Fatigue 1996;18:33-9. doi:10.1016/0142-1123(95)00076-3.

[10] de Freitas M. Multiaxial fatigue: From materials testing to life prediction. Theor Appl Fract Mech 2017;92:360-72. doi:10.1016/j.tafmec.2017.05.008.

[11] Bold PE, Brown MW, Allen RJ. A review of fatigue crack growth in steels under mixed mode I and II loading. Fatigue Fract Eng Mater Struct 1992;15:965-77. doi:10.1111/j.1460-2695.1992.tb00025.x.

[12] Plank R, Kuhn G. Fatigue crack propagation under non-proportional mixed mode loading. Eng Fract Mech 1999;62:203-29. doi:10.1016/S0013-7944(98)00097-6.

[13] Baptista R, Cláudio RA, Reis L, Madeira JFA, Freitas M. Numerical study of inplane biaxial fatigue crack growth with different phase shift angle loadings on optimal specimen geometries. Theor Appl Fract Mech 2016;85:16-25. doi:10.1016/j.tafmec.2016.08.025.

[14] Misak HE, Perel VY, Sabelkin V, Mall S. Crack growth behavior of 7075-T6 under biaxial tension-tension fatigue. Int J Fatigue 2013;55:158-65. doi:10.1016/j.ijfatigue.2013.06.003.

[15] Qian C, Wang M-. Mixed-mode fatigue crack growth in stainless steels under 
biaxial loading 1996;118:4-10.

[16] Liu A, Dittmer D. Effect of multiaxial loading on crack growth. Volume 2. Compilation of experimental data 1978.

[17] Lee EU, Taylor RE. Fatigue behavior of aluminum alloys under biaxial loading. Eng Fract Mech 2011;78:1555-64. doi:10.1016/j.engfracmech.2010.11.005.

[18] Wolf CH, Henkel S, Burgold A, Qiu Y, Kuna M, Biermann H. Investigation of fatigue crack growth under in-phase loading as well as phase-shifted loading using cruciform specimens. Crack Paths 2018.

[19] Sherry A., Lidbury DP., Bass B., Williams P. Developments in local approach methodology with application to the analysis/re-analysis of the NESC-1 PTS benchmark experiment. Int J Press Vessel Pip 2001;78:237-49. doi:10.1016/S0308-0161(01)00022-9.

[20] Bass B., McAfee W., Williams P., Pennell W. Fracture assessment of shallowflaw cruciform beams tested under uniaxial and biaxial loading conditions. Nucl Eng Des 1999;188:259-88. doi:10.1016/S0029-5493(99)00035-7.

[21] Giner E, Sukumar N, Tarancón JE, Fuenmayor FJ. An Abaqus implementation of the extended finite element method. Eng Fract Mech 2009;76:347-68. doi:10.1016/j.engfracmech.2008.10.015.

[22] Williams ML. Stress singularities resulting from various boundary conditions in angular corners of plates in extension. J Appl Mech 1952;19:526-8.

[23] Gdoutos EE. Fracture Mechanics Criteria and Applications. Springer Netherlands; 1990.

[24] Nuismer RJ. An energy release rate criterion for mixed mode fracture. Int J Fract 1975;11:245-50. doi:10.1007/BF00038891.

[25] Cotterell B, Rice JR. Slightly curved or kinked cracks. Int J Fract 1980;16:155- 
69. doi:10.1007/BF00012619.

[26] Erdogan F, Sih GC. On the crack extension in plates under plane loading and transverse shear. J Basic Eng 1963;85:519. doi:10.1115/1.3656897.

[27] Sih GC. Strain-energy-density factor applied to mixed mode crack problems. Int J Fract 1974;10:305-21. doi:10.1007/BF00035493.

[28] Palaniswamy K, Knauss WG. Propagation of a crack under general, in-plane tension. Int J Fract Mech 1972;8:114-7. doi:10.1007/BF00185207.

[29] Williams JG, Ewing PD. Fracture under complex stress? The angled crack problem. Int J Fract Mech 1972;8:441-6. doi:10.1007/BF00191106.

[30] Wang MO, Hu RH, Qian CF, Li JCM. Fatigue crack growth under mode II loading. Fatigue Fract Eng Mater Struct 1995;18:1443-54. doi:10.1111/j.14602695.1995.tb00867.x.

[31] Hourlier F, D'Hondt H, Truchon M, Pineau A. Fatigue crack path behavior under polymodal fatigue. Multiaxial Fatigue, 100 Barr Harbor Drive, PO Box C700, West Conshohocken, PA 19428-2959: ASTM International; 1985, p. 228-22821. doi:10.1520/STP36226S.

[32] Dubourg M, Lamacq V. Stage II crack propagation direction determination under fretting fatigue loading: a new approach in accordance with experimental observations. Frett. Fatigue Curr. Technol. Pract., 100 Barr Harbor Drive, PO Box C700, West Conshohocken, PA 19428-2959: ASTM International; 2000, p. 436-436-15. doi:10.1520/STP14746S.

[33] Giner E, Sabsabi M, Ródenas JJ, Javier Fuenmayor F. Direction of crack propagation in a complete contact fretting-fatigue problem. Int J Fatigue 2014;58:172-80. doi:10.1016/j.ijfatigue.2013.03.001.

[34] Marco M, Infante-García D, Díaz-Álvarez J, Giner E. Relevant factors affecting 
the direction of crack propagation in complete contact problems under fretting fatigue. Tribol Int 2019;131:343-52. doi:10.1016/j.triboint.2018.10.048.

[35] Highsmith, Shelby J. Crack path determination for non-proportional mixed-mode fatigue. Georgia Institute of Technology, 2009.

[36] Walker $\mathrm{K}$. The effect of stress ratio during crack propagation and fatigue for 2024-T3 and 7075-T6 aluminum. Eff. Environ. Complex Load Hist. Fatigue Life, 100 Barr Harbor Drive, PO Box C700, West Conshohocken, PA 19428-2959:

ASTM International; 1970, p. 1-1-14. doi:10.1520/STP32032S. 